\title{
Prozercon sellnicki Halašková, 1963: A new record of zerconid mites (Acari, Zerconidae) for the Turkish Fauna*
}

\author{
Rasit Urhan (Corresponding author) \\ Department of Biology, Faculty of Arts \& Sciences, Pamukkale University, Denizli, Turkey \\ E-mail: rurhan@pau.edu.tr \\ Elif Hilal Duran \\ Department of Biology, Faculty of Arts \& Sciences, Pamukkale University, Denizli, Turkey \\ E-mail: elifhilalduran@ @otmail.com \\ Mehmet Karaca \\ Program of Biomedical Device Technology, Department of Electronic and Automation, Denizli \\ Vocational School of Technical Sciences, Pamukkale University, Denizli, Turkey. \\ E-mail: karacamehmet@pau.edu.tr
}

This study is financially supported by the Scientific and Technological Research Council of Turkey

(TUBITAK), with $118 \mathrm{Z101}$ project number.

\begin{abstract}
During a study conducted to determine fauna of zerconid mites of Coastal Aegean Region and to contribute to the knowledge of zerconid fauna in Turkey, litter, soil and moss samples collected from different habitats were examined. A total of 26 female, 9 male and 5 deutonymph specimens of Prozercon sellnicki Halašková, 1963 were determined for the first time from Turkey.
\end{abstract}

Keywords: Acari, Prozercon sellnicki, New record, Coastal Aegean Region, Systematic, Turkey.

DOI: $10.7176 / \mathrm{JSTR} / 5-12-28$

\section{Prozercon sellnicki Halašková, 1963: Türkiye faunası için yeni bir zerkonid akar (Acari, Zerconidae) kaydı*}

\footnotetext{
*Bu çalışmanin özeti 5-8 Eylül 2019 tarihleri arasında Erzurum'da düzenlenen EJONS (8th International Congress on Mathematics, Engineering, Natural \& Medical Sciences)'da poster olarak sunulmuştur.
}

Özet

Kıyı Ege Bölgesi’nin zerkonid akar faunasını belirlemek ve Türkiye zerkonid faunasına katkıda bulunmak amacıyla gerçekleștirilen bir çalışma sırasında, farklı habitatlardan toplanan döküntü, toprak ve yosun örnekleri incelendi. Araştırma alanında Prozercon sellnicki Halašková, 1963 türüne ait toplam 26 dişi, 9 erkek ve 5 deutonimf bireyi Türkiye'den ilk defa tespit edildi.

Anahtar Kelimeler: Acari, Prozercon sellnicki, Yeni kayıt, Kıyı Ege Bölgesi, Sistematik, Türkiye. 


\section{Giriș}

Orman tabanında bulunan döküntü içinde çok sayıda küçük eklembacaklı hayvan mevcuttur. Bunların çoğunu da akarlar oluşturur (Hart ve ark. 1999). Akarlar hem tür hem de birey sayısı bakımından zengin hayvan gruplarından biridir. $\mathrm{Bu}$ canlılar, organik maddenin ayrışmasına, humus sentezine, biyolojik elementlerin korunmasına, mantar, bakteri metabolizmasının uyarılmasına katkıda bulunurlar ve toprağın biyolojik verimliliğinde önemli rolleri vardır. Mikroorganizmalar akarlarla birlikte faaliyet gösterdikleri zaman tek başına oldukları zamankinden beş kat daha hızlı olarak organik maddeyi ayrıştırmaktadır (Ghilarov, 1963). Zerconidae familyası içinde incelenen zerkonid akarlar da toprak faunasının önemli üyelerinden biridir. Bu akarların vücut uzunlukları 200-700 mikrometre arasında değişir (Duran ve Urhan, 2017). Bazı çevresel değişikliklerin incelenmesinde indikatör canlı olarak kullanılabilecekleri belirtilmiştir (Sikora, 2014).

\section{Materyal ve Yöntem}

Bu çalışmanın ana materyalini, Kıyı Ege Bölgesi'nin farklı habitatlarından toplanan döküntü, toprak ve yosun örnekleri oluşturmaktadır. Naylon torbalara konularak etiketlenip laboratuvara getirilen örnekler, birleştirilmiş Berlese hunilerinden oluşan ayıklama cihazına yerleştirilerek ayıklandı. Örneklerin ağartılmasında ve temizlenmesinde \%60'lık laktik asit kullanıldı. Mikroskobik incelemeler genellikle gliserinli ortamda yapıldı. Ancak farklı konumlarda incelenmesi gerektiğinde Hoyer ortamında sabit preparatları hazırlandı. İncelenmesi tamamlanarak tanımları yapılan örneklerin mikroskopta (DP25 kameralı Olympus CX41) şekilleri çizildi, çeşitli vücut kısımlarının ölçümleri yapıldı. Vücut ve kıl ölçüleri $\mu \mathrm{m}$ cinsinden ölçüldü ve ortalama olarak verildi. Daha sonra incelenen örnekler, içinde \% 70 'lik alkol ve 1-3 damla gliserin bulunan saklama şişelerine konulup etiketlendi. Türlerin teşhis işlemlerinde Mašán ve Fend’a (2004) terminolojisi kullanılmıştır.

\section{Bulgular}

Bu çalışmada, Kıyı Ege Bölgesi illerinden olan Aydın, İzmir ve Manisa’nın farklı habitatlarından toplanan zerkonid akarlar değerlendirildi ve Türkiye akar faunası için yeni kayıt olan Prozercon sellnicki

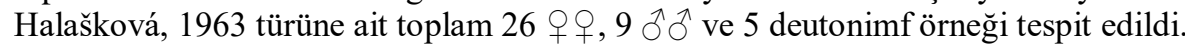

Prozercon sellnicki Halašková, 1963

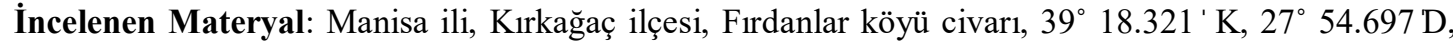
395 m, 07.01.2019, mazı meşesi (Quercus infectoria) ve kızılçam (Pinus brutia) altından döküntü ve toprak örneği, 11 + $9,6 \widehat{\jmath}, 5 \mathrm{DN}$. Aydın ili, Köşk ilçesi, Ödemiş - Köşk yolu, Akçaköy mahallesi, $37^{\circ}$ $57.625^{\prime} \mathrm{K}, 28^{\circ} 01.383$ D, 656 m, 10.06.2019, ardiç (Juniperus sp.) ve karaservi (Cupressus sempervirens) altından döküntü ve toprak örneği, 39 ㅇ, $10^{\lambda}$. Aydın ili, Köşk ilçesi, Ödemiş - Köşk yolu, Köşs’e 16 km kala, $37^{\circ} 56.866 \mathrm{~K}, 28^{\circ} 01.571$ D, $452 \mathrm{~m}, 10.06 .2019$, Makedonya meşesi (Quercus trojana) altından

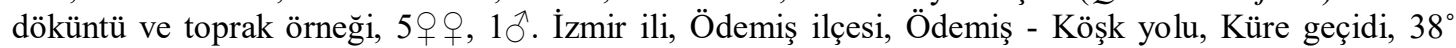
03.166 K, $27^{\circ} 59.467$ D, $933 \mathrm{~m}, 26.08 .2019$, saçlı meşe (Quercus cerris) altından döküntü ve toprak örneği, 7 우, $1 \jmath^{\top}$.

\section{Díşi̇ (Şekil $1 \mathrm{~A})$}

Vücut 322 / $229 \mu \mathrm{m}$ büyüklüğündedir.

Podonotum üzerindeki $j_{5}$ kılı kısa ve düz, geriye kalan kılların tamamı tüylü yapıdadır. Opistonotum üzerindeki kenar kılları ( $R$ kıl dizisi) hariç bütün kıllar tüylü yapıdadır. $J_{1}$ kılı $J_{2}$ k1lı kaidesine, $J_{2}$ kılı $J_{3}$ k1lı kaidesine, $J_{5}$ k1lı $J_{6}$ k1lı kaidesine uzanmaz. $Z_{2}$ kılı $Z_{3}$ k1lı kaidesine kadar uzanmaz. $S_{1}$ kılı tüylü ve boyut olarak neredeyse $Z_{1}$ kılına eşittir. $S_{2-4}$ kılları boyut ve yapı olarak hemen hemen aynıdır (firça benzeri, tüylü). $R$ kılları kısa ve düzdür. $Z_{5}-J_{6}$ kılları arasındaki mesafe $29 \mu$ m'dir. Opistonotum üzerindeki kılların uzunlukları ve aralarındaki mesafeler Tablo 1 'de gösterilmiştir.

Podonotum kiremitvari desenlidir. Podonotum ve opistonotum üzerindeki gözeneklerin konumları Şekil 1A'da görüldüğü gibidir. Sırt çukurlukları belirgin, iyi kitinleşmiş ve dışta yer alan sırt çukurlukları içtekilerden iki kat daha büyüktür.

Peritremal plağın şekli ve k1l düzeni cinsin tipik özelliğine uygundur. Adgenital plaklar ve $g v_{2}$ bezi yoktur. Ventroanal plağın ön kenarında 2 tane kıl vardır.

\section{ERKEK (Şekil 1 B)}

Vücut 275 / $193 \mu \mathrm{m}$ büyüklüğündedir.

Podonotum ve opistonotum üzerindeki kıllar, gözenekler ve desen bakımından dişiye benzerdir. $Z_{5}-J_{6}$ k1lları arasındaki mesafe $25 \mu \mathrm{m}$ 'dir. Opistonotum üzerindeki kılların uzunlukları ve bu kıllar arasındaki mesafeler Tablo 1'de gösterilmiştir. 


\section{DEUTONIMF (Şekil $1 \mathrm{C}$ )}

Vücut 278 / $196 \mu$ m büyüklüğündedir.

Podonotum üzerindeki $j_{1}, j_{3}, z_{2}, s_{5}, r_{1}, r_{4}, r_{6}$ ve $r_{7}$ k1lları tüylü, geriye kalan k1lların tamamı düzdür. Opistonotum üzerindeki $R$ kıları kısa ve düz, geriye kalan kılların tamamı tüylüdür. Podonotum ve opistonotum üzerindeki gözeneklerin konumları ergin bireylerdeki gibidir. $Z_{5}-J_{6}$ kılları arasındaki mesafe $20 \mu$ m'dir. Opistonotum üzerindeki kılların uzunlukları ve bu kıllar arasındaki mesafeler Tablo 1'de gösterilmiştir.

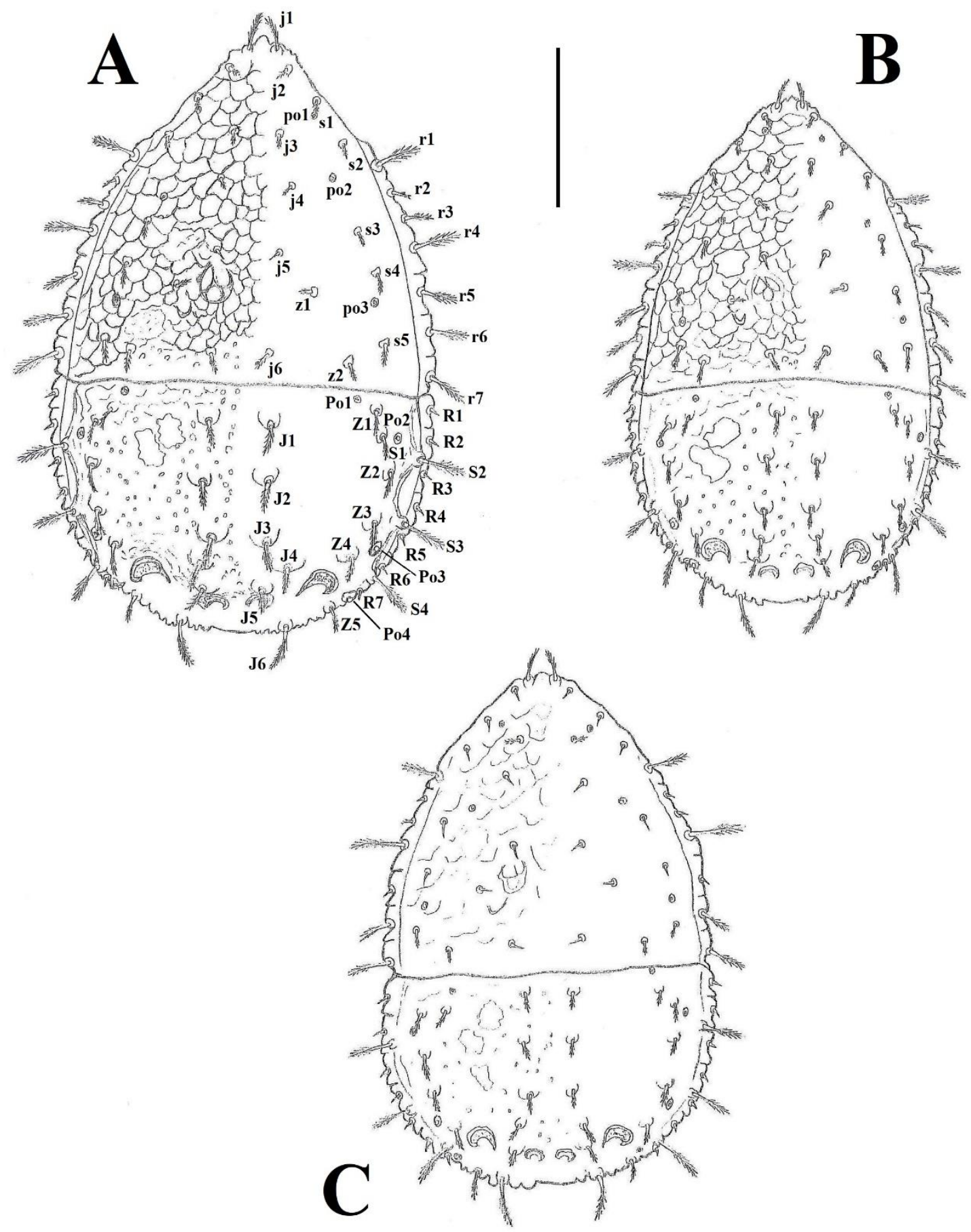

Şekil 1. Prozercon sellnicki: A) Dişi, üstten, B) Erkek, üstten, C) Deutonimf, üstten (Ölçek $100 \mu$ m). 
Tablo 1. Prozercon sellnicki türünün dişi (), erkek (ð) ve deutonimflerinde (DN) opistonotum üzerindeki kılların uzunlukları ve bu kıllar arasındaki mesafeler ( $\mu$ m olarak).

\begin{tabular}{|c|c|c|c|c|c|c|c|c|c|c|c|}
\hline Kıl & 우 ㅇ & $\hat{\sigma} \widehat{\sigma}$ & DN & Kll & $q q$ & $\hat{0} \hat{\sigma}$ & DN & Kıl & $q$ q & $\hat{0} \hat{\sigma}$ & DN \\
\hline$J_{1}$ & 17 & 13 & 12 & $Z_{1}$ & 14 & 10 & 11 & $S_{1}$ & 18 & 13 & 11 \\
\hline$J_{1}-J_{2}$ & 33 & 26 & 27 & $Z_{1}-Z_{2}$ & 35 & 28 & 29 & $S_{1}-S_{2}$ & 29 & 22 & 21 \\
\hline$J_{2}$ & 15 & 11 & 10 & $Z_{2}$ & 13 & 12 & 12 & $S_{2}$ & 29 & 22 & 34 \\
\hline$J_{2}-J_{3}$ & 35 & 26 & 32 & $Z_{2}-Z_{3}$ & 26 & 23 & 25 & $S_{2}-S_{3}$ & 36 & 30 & 30 \\
\hline$J_{3}$ & 14 & 13 & 9 & $Z_{3}$ & 15 & 13 & 12 & $S_{3}$ & 28 & 24 & 36 \\
\hline$J_{3}-J_{4}$ & 20 & 17 & 17 & $Z_{3}-Z_{4}$ & 26 & 22 & 24 & $S_{3}-S_{4}$ & 35 & 28 & 29 \\
\hline$J_{4}$ & 14 & 10 & 8 & $Z_{4}$ & 14 & 9 & 9 & $S_{4}$ & 28 & 25 & 33 \\
\hline$J_{4}-J_{5}$ & 14 & 9 & 11 & $Z_{4}-Z_{5}$ & 29 & 24 & 21 & & & & \\
\hline$J_{5}$ & 11 & 8 & 7 & $Z_{5}$ & 16 & 17 & 13 & & & & \\
\hline$J_{5}-J_{6}$ & 23 & 16 & 18 & & & & & & & & \\
\hline$J_{6}$ & 28 & 24 & 28 & & & & & & & & \\
\hline$J_{6}-J_{6}$ & 61 & 51 & 57 & & & & & & & & \\
\hline
\end{tabular}

\section{Tartışma ve Sonuç}

Prozercon sellnicki'nin dünya genelinde Almanya, Çekya, Hırvatistan, Letonya, Polonya, Slovakya ve Ukrayna'dan yayılış kayıtları mevcuttur (Mašán ve Fend’a, 2004; Ujvári, 2006, Karaca ve Urhan, 2019). Türkiye akar faunasına katkıda bulunmak ve Kıyı Ege Bölgesi'nin zerkonid akar faunasını belirlemek amacıyla Aralık 2018 - Aralık 2019 tarihleri arasında araştırma alanında çeşitli habitatlardan döküntü, çürümüş ağaç kökleri, yosun ve toprak örnekleri toplandı. Bu örneklerin laboratuar ortamında analizleri sonucunda Türkiye akar faunası için yeni kayıt olan Prozercon sellnicki türüne ait bireyler Aydın, İzmir ve Manisa illerinde tespit edildi. Dört farklı lokalitede 6 farklı habitattan toplanan örneklerin içerisinde 26 dişi, 9 erkek ve 5 deutonimf bireyi bulundu. Örneklerimizin yapısal özellikleri tip örnekleriyle uygunluk göstermektedir. Dişiler için örneklerimizin vücut büyüklüğü yönünden (322 / $229 \mu \mathrm{m})$ hemen hemen tip örneklerinin vücut büyüklüğü ile $(312 / 237 \mu \mathrm{m})$ aynı boyutlarda olduğu anlaşılmaktadır. Türün deutonimf bireyleri için de aynı durum söz konusudur. Türkiye akar faunası için yeni kayıt olarak tespit edilen bu türle birlikte ülkemizden bilinen Prozercon türlerinin sayısı 39'a yükselmiştir (Urhan ve ark. 2019; 2020). Yapılan ve gelecekte yapılacak olan benzer çalışmalarla Türkiye akar faunasına ciddi katkı sağlanacağı düşünülmektedir.

\section{Teşekkür}

Bu çalışma, TÜBİTAK (Türkiye Bilimsel ve Teknolojik Araştırma Kurumu) tarafından $118 Z 101$ nolu proje ile desteklenmiştir.

\section{Kaynaklar}

Duran, E.H., Urhan, R. (2017). Zerconid mites (Acari, Zerconidae) in İstanbul, with four new records for the Turkish fauna. Turkish Journal of Zoology, 41: 931-939.

Ghilarov, M. S. (1963). Soil Organizm. 1. Doeksen and Von Der Drift, Holland, Amsterdam, NorthHolland Publishing Company, 255-259.

Halašková, V. (1963). Mixozercon n. g., a new genus of the family Zerconidae (Acari). Acta Universitalis Carolinae-Biologica, 2: 203-208. 
Hart, C., Morris, C., Baudo, B., Degrout, K. (1999). Leaf litter decomposition and litter fauna. Stosktonia, 2: 18-21.

Karaca, M., Urhan, R. (2019). Species list of zerconid mites (Acari: Mesostigmata: Zerconidae) of Czech Republic. 5th International Conference on Engineering and Natural Science, p. 36-40, Prague (Czech Republic), 12-16 June.

Mašán, P., Fend'a, P. (2004). Zerconid mites of Slovakia (Acari, Mesostigmata, Zerconidae). Slovak Academy of Sciences, Institute of Zoology Bratislava, $238 \mathrm{pp}$.

Sikora, B. (2014). Mites of the family Zerconidae (Acari: Mesostigmata) of the Nearctic region. Annales Zoologici, 64: 131-250.

Ujvári, Z. (2006). New records of zerconid mites (Acari: Mesostigmata) from Mts. Papuk, Croatia, with description of Zercon kontschani sp. n. Opuscula Zoologica Budapest, 37: 63-70.

Urhan, R., Karaca, M., Duran, E.H., Aksu, B., Bilki, K. (2019). A new record of the family Zerconidae (Acari: Mesostigmata) from Turkey: Prozercon rekaae Ujvári, 2008. 5th International Conference on Engineering and Natural Science, p. 100-104, Prague (Czech Republic), 12-16 June.

Urhan, R., Karaca, M., Duran, E.H. (2020). Description of Prozercon miraci sp. nov. (Acari: Mesostigmata: Zerconidae) from Coastal Aegean Section in Turkey, with a key to the Turkish species. Acarological Studies. 